\title{
Haze Effects on Satellite Remote Sensing Imagery and their Corrections
}

\author{
Asmala Ahmad ${ }^{1}$, Mohd Mawardy Abdullah ${ }^{5}$ \\ Centre for Advanced Computing Technology (C-ACT) \\ Fakulti Teknologi Maklumat dan Komunikasi (FTMK) \\ University Teknikal Malaysia Melaka (UTeM) \\ Melaka, Malaysia \\ Shaun Quegan ${ }^{2}$ \\ School of Mathematics and Statistics \\ University of Sheffield, Sheffield, United Kingdom
}

\author{
Suliadi Firdaus Sufahani ${ }^{3}$ \\ Fakulti Sains Gunaan dan Teknologi \\ Universiti Tun Hussein Onn Malaysia \\ Johor, Malaysia
}

\author{
Hamzah Sakidin ${ }^{4}$ \\ Department of Fundamental and Applied Sciences \\ Universiti Teknologi PETRONAS \\ Perak, Malaysia
}

\begin{abstract}
Imagery recorded using satellite sensors operating at visible wavelengths can be contaminated by atmospheric haze that originates from large scale biomass burning. Such issue can reduce the reliability of the imagery and therefore having an effective method for removing such contamination is crucial. The principal aim of this study is to investigate the effects of haze on remote sensing imagery and develop a method for removing them. In order to get a better understanding on the behaviour of haze, the effects of haze on satellite imagery were initially studied. A methodology of removing haze based on haze subtraction and filtering was then developed. The developed haze removal method was then evaluated by means of signal-to-noise ratio (SNR) and classification accuracy. The results show that the haze removal method is able to improve the haze-affected imagery qualitatively and quantitatively.
\end{abstract}

Keywords-Haze effects; haze removal; remote sensing; accuracy; visibility

\section{INTRODUCTION}

Haze occurs almost every year in Malaysia and is caused by smoke that originates from forest fires in nearby regions. The recent September 2019 haze was considered among the worst as the air pollutant index (API) in Sri Aman, Sarawak reached 407 indicating 'hazardous level' [1] . Previously, the worst haze episode was recorded in 1997 when API in Miri, Sarawak hit 839 ('emergency level'). This was followed by 2005 (541 in Kuala Selangor), 2010 (432 in Muar), 2013 (762 in Muar) and 2015 (308 in Shah Alam) [2]. Haze causes visibility to drop and therefore affecting the images acquired for this area using optical sensor such as that onboard the Landsat-5 TM satellite. In Malaysia, haze monitoring is carried out by the Malaysian Meteorological Department and Department of Environment Malaysia in terms of visibility and API respectively. Malaysia has a typical tropical monsoon climate characterized by uniformly high mean temperature with temperature approximately $27 \mathrm{oC}$, a relatively high mean annual rainfall that exceeds $2000 \mathrm{~mm}$ per year and humidity $70 \%$ to $90 \%$ throughout the year. The wind over the country is generally mild and variable. However, there are some periodic changes in the wind flow patterns that describe the two monsoon seasons namely the north-east monsoon, known as the wet season that occurs from November to March and the south-west monsoon, known as the dry season that occurs from June to September. The remaining months, April to May and October to November, are known as the transitional periods. Because the wind comes from the south-west and there is much less rain during the south-west monsoon and the second transitional period, smoke from the forest fires in Sumatra remains suspended in the atmosphere for a long time and drifts to Malaysia, causing haze. This paper focuses on the 2005 haze episode that caused a drop in visibility in most places in Malaysia. Fig. 1 shows photos of clear and hazy conditions in Putrajaya, the federal administrative centre of Malaysia, located about $30 \mathrm{~km}$ from Kuala Lumpur. Due to the hazardous properties of the haze constituents, a sudden increase in respiratory and eye-related illnesses cases was reported. The drop in visibility conditions also badly affected economyrelated activities including tourism, transportation, fisheries and production sectors, which caused a big loss to Malaysia.

Visibility measurement is carried out by the Malaysian Meteorological Department on a daily basis through a network of 149 monitoring stations. For public convenience, haze severity is categorised into five levels; visibilities more than 10 $\mathrm{km}$ represent 'clear', 5 to $10 \mathrm{~km}$ visibilities represent 'moderate', 2 to $5 \mathrm{~km}$ visibilities represent 'hazy', 0.5 to $2 \mathrm{~km}$ visibilities represent 'very hazy' and visibilities less than 0.5 km represent 'extremely hazy' (Table I).

The Department of Environment Malaysia operates a network of 51 stations, where 36 stations are in West Malaysia (or Peninsular Malaysia) and 15 in East Malaysia. Due to the potential harm to human health, five main pollutants are measured which are $\mathrm{SO}_{2}, \mathrm{NO}_{2}, \mathrm{CO}, \mathrm{O}_{3}$ and $\mathrm{PM}_{10}$ [4]. Based on their locations and the types of pollutant measured, the stations are categorised into Residential (20 stations), Industrial (12 stations), Traffic (1 station), Background (1 station) and $\mathrm{PM}_{10}$ (2 stations). The difference between these categories is the types of pollutant measured (Table II). The location of air quality monitoring stations in West Malaysia and a typical monitoring station are shown in Fig. 2 [5]. 


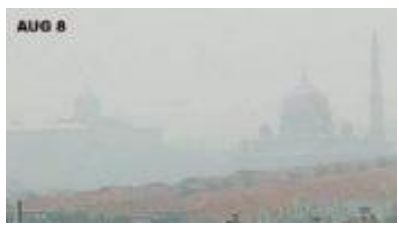

(a)

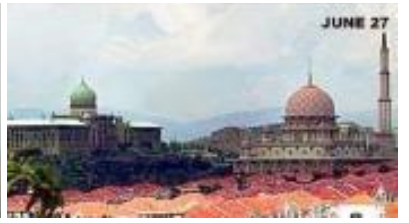

(b)
Fig. 1. Putrajaya, the Federal Administrative Centre for Malaysia During (a) Hazy (8 August 2005) and (b) Clear (27 June 2005) [3].

TABLE. I. VISIBILITY LEVELS USED BY THE MALAYSIAN METEOROLOGICAL DEPARTMENT [6]

\begin{tabular}{|l|l|}
\hline Severity & Horizontal Visibility $(\mathrm{km})$ \\
\hline Clear & $>10$ \\
\hline Moderate & $5-10$ \\
\hline Hazy & $2-5$ \\
\hline Very hazy & $0.5-2$ \\
\hline Extremely hazy & $<0.5$ \\
\hline
\end{tabular}

TABLE. II. Station CATEgories AND THE TyPe OF POLLUtANTS MEASURED

\begin{tabular}{|l|l|l|l|l|l|}
\hline Category & $\mathrm{SO}_{2}$ & $\mathrm{NO}_{2}$ & $\mathrm{CO}$ & $\mathrm{O}_{3}$ & $\mathrm{PM}_{10}$ \\
\hline Industrial & $\mathrm{X}$ & $\mathrm{X}$ & - & - & $\mathrm{X}$ \\
\hline Residential & $\mathrm{X}$ & $\mathrm{X}$ & $\mathrm{X}$ & $\mathrm{X}$ & $\mathrm{X}$ \\
\hline Traffic & $\mathrm{X}$ & $\mathrm{X}$ & - & $\mathrm{X}$ & $\mathrm{X}$ \\
\hline Background & $\mathrm{X}$ & $\mathrm{X}$ & $\mathrm{X}$ & $\mathrm{X}$ & $\mathrm{X}$ \\
\hline $\mathrm{PM}_{10}$ & - & - & - & - & $\mathrm{X}$ \\
\hline
\end{tabular}

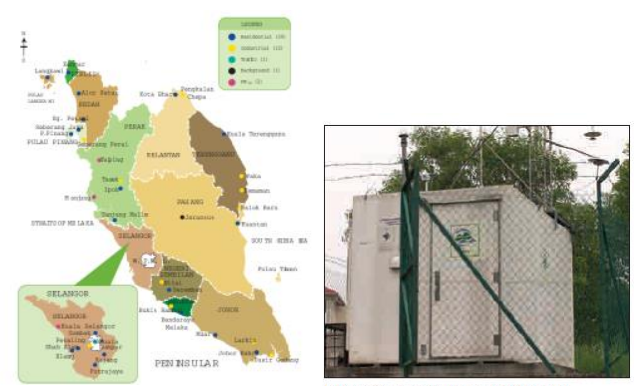

Fig. 2. Location of Air Quality Monitoring Stations in West Malaysia (Left) with an Enlarged Version of Selangor State (Sub-section in the Lower Left) and a Typical Monitoring Station (Right) [5].

In the API system, the air quality levels are categorised into: good $(0-50)$, moderate $(51-100)$, unhealthy $(101-$ $200)$, very unhealthy $(201-300)$, hazardous $(300-500)$ and emergency (> 500) (Table III). The API value reported for a given time period represents the highest API value among all pollutants during that particular time period; the predominant pollutant during haze episodes is $\mathrm{PM}_{10}[6]$.

The Recommended Malaysian Air Quality Guidelines forms the basis for calculating the API and consists of two key aspects: the averaging time and the Malaysian guidelines (Table IV) [4]. The averaging time differs for different air pollutants and represents the period of time over which the measurements are made and recorded in running averages. For reporting purposes, the same averaging times are used: $\mathrm{PM}_{10}$ and $\mathrm{SO}_{2}$ (24-hour running averages), $\mathrm{CO}$ (8-hour running averages), and $\mathrm{O}_{3}$ and $\mathrm{NO}_{2}$ (1-hour running averages). The Malaysian guidelines represent the safe level for each pollutant and were derived based on human health data and recommendations from the World Health Organisation (WHO). For example, a $\mathrm{PM}_{10}$ concentration of $150 \mu \mathrm{g} / \mathrm{m}^{3}$ corresponds to $100 \mathrm{API}$, and is the upper limit for the safe level; $\mathrm{PM}_{10}$ concentrations exceeding this are likely to cause adverse health effects. Conversion of the $\mathrm{PM}_{10}$ concentration from $\mu \mathrm{g} / \mathrm{m}^{3}$ to API can be done using the equations shown in Table V.

TABLE. III. API RANGe, Status, LeVEl of Pollution AND HeAlth MEASURE [4]

\begin{tabular}{|c|c|c|c|}
\hline API & Status & Level of Pollution & Health Measure \\
\hline 0 to 50 & Good & $\begin{array}{l}\text { Low, no ill effects } \\
\text { on health. }\end{array}$ & $\begin{array}{l}\text { No restriction of } \\
\text { activities to all groups. }\end{array}$ \\
\hline 51 to 100 & Moderate & $\begin{array}{l}\text { Moderate, no ill } \\
\text { effects on health. }\end{array}$ & $\begin{array}{l}\text { No restriction of } \\
\text { activities to all groups. }\end{array}$ \\
\hline 101 to 200 & Unhealthy & $\begin{array}{l}\text { Mild aggravation of } \\
\text { symptoms and } \\
\text { decreased exercise } \\
\text { tolerance in persons } \\
\text { with heart or lung } \\
\text { disease. }\end{array}$ & $\begin{array}{l}\text { Restriction of outdoor } \\
\text { activities for high-risk } \\
\text { persons. General } \\
\text { population should } \\
\text { reduce vigorous } \\
\text { outdoor activity. }\end{array}$ \\
\hline 201 to 300 & $\begin{array}{l}\text { Very } \\
\text { Unhealthy }\end{array}$ & $\begin{array}{l}\text { Significant } \\
\text { aggravation of } \\
\text { symptoms and } \\
\text { decreased exercise } \\
\text { tolerance in persons } \\
\text { with heart or lung } \\
\text { disease. }\end{array}$ & $\begin{array}{l}\text { Elderly and persons } \\
\text { with known heart or } \\
\text { lung disease should } \\
\text { stay indoors and } \\
\text { reduce physical } \\
\text { activity. General } \\
\text { population should } \\
\text { reduce vigorous } \\
\text { outdoor activity. Those } \\
\text { with any health } \\
\text { problems to consult } \\
\text { doctor }\end{array}$ \\
\hline $300-500$ & Hazardous & $\begin{array}{l}\text { Severe aggravation } \\
\text { of symptoms and } \\
\text { endangers health. }\end{array}$ & $\begin{array}{l}\text { Elderly and persons } \\
\text { with existing heart or } \\
\text { lung disease should } \\
\text { stay indoors and } \\
\text { reduce physical } \\
\text { activity. General } \\
\text { population should } \\
\text { reduce vigorous } \\
\text { outdoor activity. }\end{array}$ \\
\hline$>500$ & Emergency & $\begin{array}{l}\text { Severe aggravation } \\
\text { of symptoms and } \\
\text { endangers health. }\end{array}$ & $\begin{array}{l}\text { General population } \\
\text { advised to follow the } \\
\text { orders of National } \\
\text { Security Council and } \\
\text { always follow } \\
\text { announcements } \\
\text { through the mass } \\
\text { media. }\end{array}$ \\
\hline
\end{tabular}

TABLE. IV. AIR QUALITy MEASUREMENT Guidelines [4]

\begin{tabular}{|l|l|l|l|}
\hline \multirow{2}{*}{ Pollutant } & \multirow{2}{*}{ Averaging Time } & \multicolumn{2}{|l|}{ Malaysian Guidelines } \\
\cline { 3 - 4 } & & $(\mathrm{ppm})$ & $\left(\mu \mathrm{gm}^{-3}\right)$ \\
\hline \multirow{2}{*}{$\mathrm{O}_{3}$} & 1 hour & 0.10 & 200 \\
\cline { 2 - 4 } & 8 hours & 0.06 & 120 \\
\hline \multirow{2}{*}{$\mathrm{CO}$} & 1 hour & 30 & 35 \\
\cline { 2 - 4 } & 8 hours & 9 & 10 \\
\hline \multirow{2}{*}{$\mathrm{NO}_{2}$} & 1 hour & 0.17 & 320 \\
\cline { 2 - 4 } & 24 hours & 0.04 & - \\
\hline \multirow{2}{*}{$\mathrm{SO}_{2}$} & 1 hour & 0.13 & 350 \\
\cline { 2 - 4 } & 24 hours & 0.04 & 105 \\
\hline \multirow{2}{*}{$\mathrm{PM}_{10}$} & & & \\
\cline { 2 - 4 } & 24 hour & \multirow{2}{*}{ N/A } & 50 \\
\cline { 2 - 4 } & 1 year & & \\
\hline
\end{tabular}


TABLE. V. EQUATIONS FOR API CALCULATION BASED ON PM 10 24-HouR RUNNING AVERAGES [4]

\begin{tabular}{|l|l|}
\hline $\mathrm{PM}_{10}$ concentration, $\mathrm{C}\left(\mu \mathrm{g} / \mathrm{m}^{3}\right)$ & Equation used for conversion to API \\
\hline $\mathrm{C} \leq 50$ & $\mathrm{API}=\mathrm{C}$ \\
\hline $50<\mathrm{C} \leq 350$ & $\mathrm{API}=50+[(\mathrm{C}-50) \times 0.5]$ \\
\hline $350<\mathrm{C} \leq 420$ & $\mathrm{API}=200+[(\mathrm{C}-350) \times 1.43]$ \\
\hline $420<\mathrm{C} \leq 500$ & $\mathrm{API}=300+[(\mathrm{C}-420) \times 1.25]$ \\
\hline $\mathrm{C} \geq 500$ & $\mathrm{API}=400+(\mathrm{C}-500)$ \\
\hline
\end{tabular}

Fig. 3 shows visibility and $\mathrm{PM}_{10}$ intensity against Landsat overpass date in 2005 for Klang Port, Petaling Jaya, Kuantan and Kota Bharu. The sudden increase in $\mathrm{PM}_{10}$ and drop in visibility in August 2005, particularly in Klang Port and Petaling Jaya, was associated with the occurrence of haze in that year. It can be seen that extreme haze occurred between 6 and 22 August 2005. Klang Port and Petaling Jaya, which are located on the west of Malaysia, with average visibility and $\mathrm{PM}_{10}$ concentration approximately $11 \mathrm{~km}$ and 70 API respectively, experienced lower visibility and higher $\mathrm{PM}_{10}$ intensity than Kuantan and Kota Bharu, with average visibility and intensity approximately $14 \mathrm{~km}$ and 40 API respectively, which are located on the east. Since extremely hazy and very hazy conditions are quite rare in Malaysia, we are more concerned on a more frequently occurring conditions, specifically moderate; in which later the haze removal will be tested onto an image with moderate haze.

Fig. 4 shows scatterplots of visibility for Petaling Jaya vs. Klang port, Petaling Jaya vs. Kuantan, Petaling Jaya vs. Kota Bharu and Kuantan vs. Kota Bharu, together with linear fits to these plots. It is clear that the visibility correlation between nearby stations, Petaling Jaya and Klang Port (0.708) is much higher than non-neighbouring stations, Petaling Jaya and Kuantan (0.04), Petaling Jaya and Kota Bharu (0.02) and Kuantan and Kota Bharu (0.08). In this thesis, the testing of the developed haze removal method will be carried out over Bukit Beruntung area, by using $\mathrm{PM}_{10}$ measurements from Petaling Jaya station.

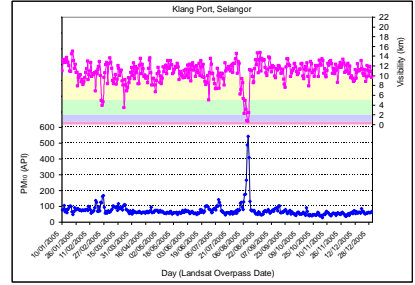

(a)

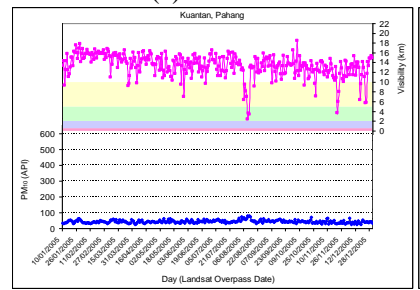

(c)

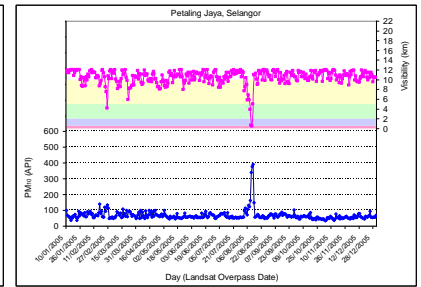

(b)

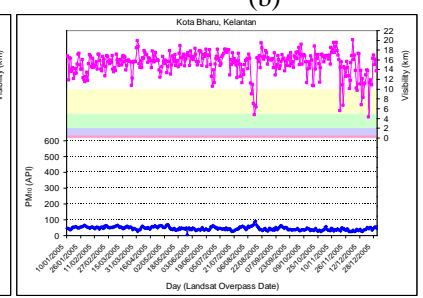

(d)
Fig. 3. Visibility and $\mathrm{PM}_{10}$ Intensity for (a) Klang Port, (b) Petaling Jaya, (c) Kuantan and (d) Kota Bharu Stations. White, Yellow, Green, Violet and Red Colours Indicate Clear (above $10 \mathrm{~km})$, Moderate $(5-10 \mathrm{~km})$, Hazy $(2-5$ $\mathrm{km})$, Very Hazy $(0.5-2 \mathrm{~km})$ and Extremely Hazy (Less than $0.5 \mathrm{~km}$ ) Conditions Respectively.

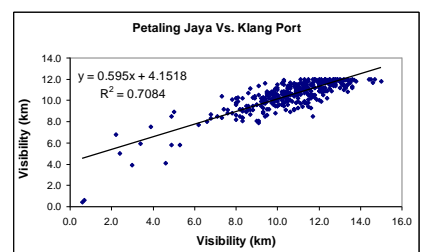

(a)

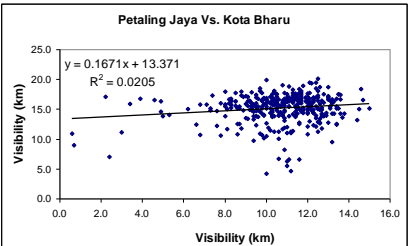

(c)

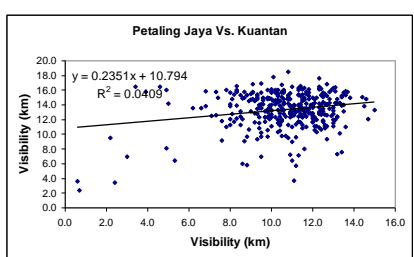

(b)

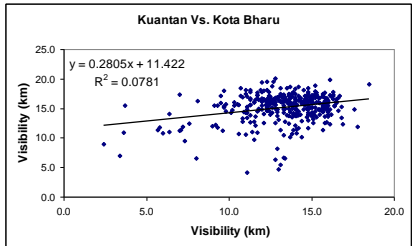

(d)
Fig. 4. Visibility Correlation for (a) Petaling Jaya vs. Klang port, (b) Petaling Jaya vs. Kuantan, (c) Petaling Jaya vs. Kota Bharu and (d) Kuantan vs. Kota Bharu.

\section{HAZE EFFECTS ON REMOTE SENSING IMAGERY}

\section{A. Simulating Hazy Images}

$6 \mathrm{SV} 1$ is the vector version of the $6 \mathrm{~S}$ (Second Simulation of the Satellite Signal in the Solar Spectrum) [7], [8], though it also works in scalar mode. The vector version is introduced to account for radiation polarisation, due to Rayleigh scattering in a mixed molecular-aerosol atmosphere, which is to be used when performing atmospheric correction. In our study, the 6SV1 was used in simulating haze effects, therefore the radiation polarisation effect was assumed negligible. Hence, our interest was in the scalar mode of 6SV1, which was similar to $6 \mathrm{~S}$.

\section{B. ML Classification on the Simulated Hazy Images}

ML classification was carried out using all 6 bands to produce 11 classes, which were coastal swamp forest, dry land forest, oil palm, rubber, cleared land, sediment plumes, water, coconut, bare land, urban and industry [9], [10], [11]. To carry out ML classification on the hazy scenes, we need training pixels within the hazy scene. For this purpose, the ROIs for different land classes (different colours) that were applied on the clear scene were used as a template. Fig. 5 shows bands 3 , 2 and 1 assigned to red, green and blue channels respectively (left). ML classification using training pixels from hazy images were performed for $20 \mathrm{~km}$ (clear) downto $0 \mathrm{~km}$ visibility (right).

\section{The Effects of Haze on the Hazy Images}

We carried out spectral signature analysis by plotting mean radiance versus band $1,2,34,5$ and 7 for all 11 land covers and for visibility $20 \mathrm{~km}$ (clear) down to $0 \mathrm{~km} \mathrm{[12].} \mathrm{The}$ outcome for visibility $16 \mathrm{~km}$ and $2 \mathrm{~km}$ are shown in Fig. 6 . Mean radiances versus bands of individual classes for a scene with haze (black) and without haze (red) were simultaneously plotted to signify the effects of haze. Vertical bars indicate standard deviations in $\mathrm{km}$ visibility. It is clear that the spectral signature of the land covers is severely modified at $2 \mathrm{~km}$ compared to $16 \mathrm{~km}$ visibility. At $16 \mathrm{~km}$ visibility the modification can be hardly seen due to the insignificant scattering that occurred and moreover it still considered as good visibility. On the other hand, significant modification can 
be seen at $2 \mathrm{~km}$ visibility indicating severe scattering particularly for bands with shorter wavelengths (band 1,2 and 3 ) compared to longer wavelengths (band 5 and 7). When the plotted together for all 11 land covers (Fig. 7), the spectral signatures get narrower at $2 \mathrm{~km}$ compared to $16 \mathrm{~km}$ visibility indicating that the land covers are becoming visually inseparable as visibility gets very low.

To understand better the effects of haze on remote sensing images, band correlation versus visibility was plotted for all possible combinations and for all 11 land covers (Fig. 8). It can be seen that for oil palm and urban, correlation gets close to ' 1 ' as visibility reduces. This is due to the fact that haze has greater effects at low visibility due to the very severe scattering that makes the radiance becomes very similar although when measured from different bands and eventually giving correlation close to ' 1 ' signifying highly correlated.

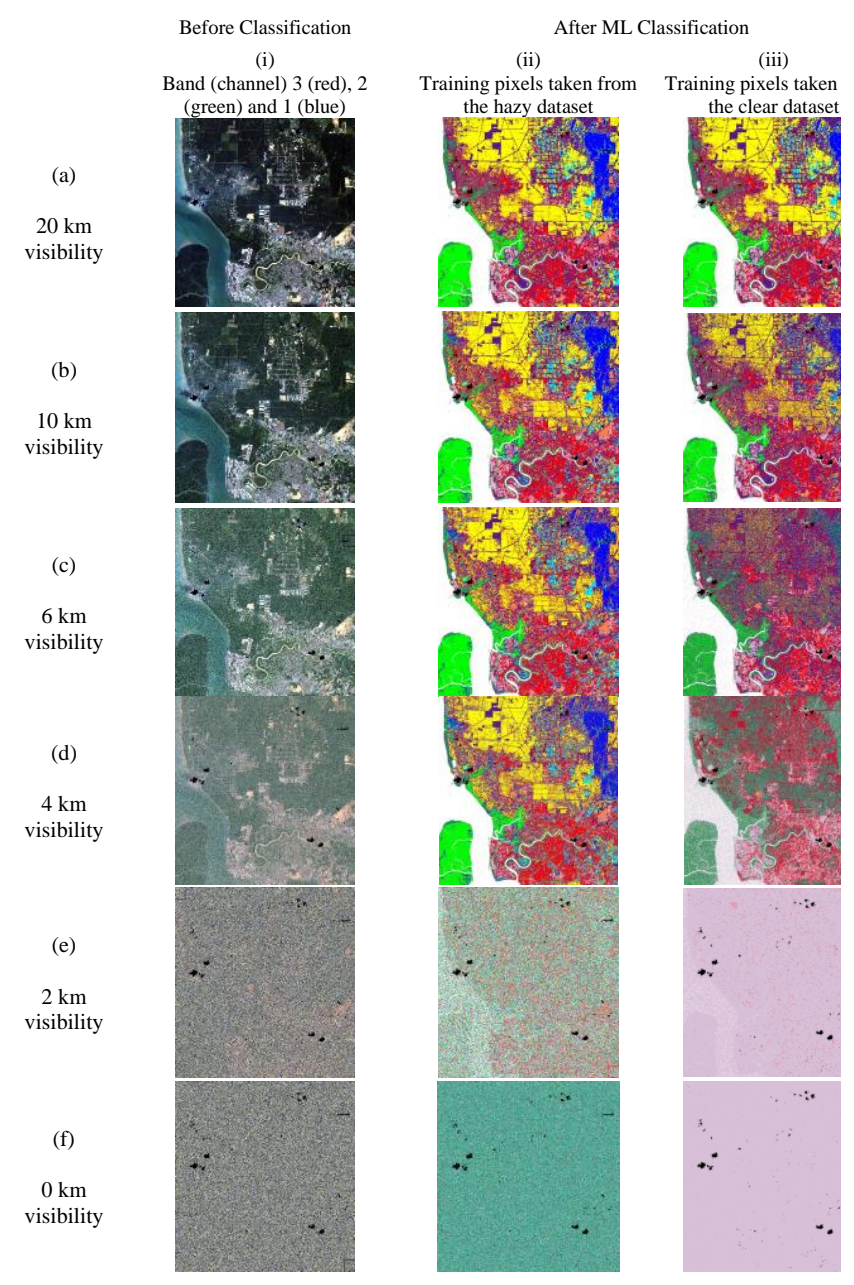

Fig. 5. Bands 3, 2 and 1 Assigned to Red, Green and Blue Channels Respectively (Left), the ML Classification using Training Pixels from Hazy Images (Middle) and ML Classification using Training Pixels from Clear Images for (a) $20 \mathrm{~km}$ (Clear), (b) $10 \mathrm{~km}$, (c) $6 \mathrm{~km}$, (d) $4 \mathrm{~km}$, (e) $2 \mathrm{~km}$ and (f) 0 $\mathrm{km}$ Visibility. Note that Images a(ii) and a(iii) are the Same and are Displayed for Convenience. Black Patches are Cloud and its Shadow (Masked Black).

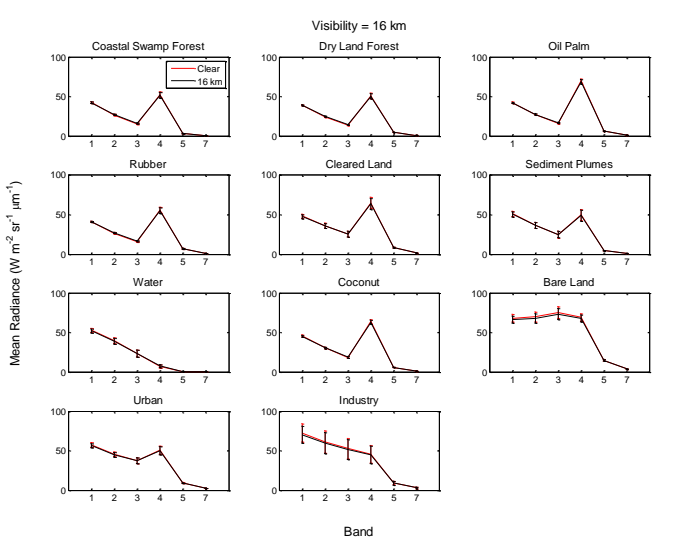

(a)
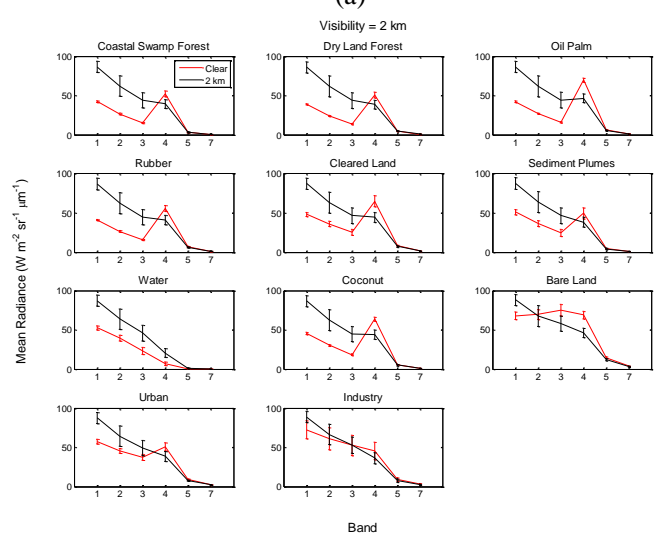

(b)

Fig. 6. Mean Radiances Versus Bands of Individual Classes for a Scene with Haze (Black) and without Haze (red) at Visibility (a) 16 and (b) 2 km. Vertical Bars Indicate Standard Deviations in km Visibility.

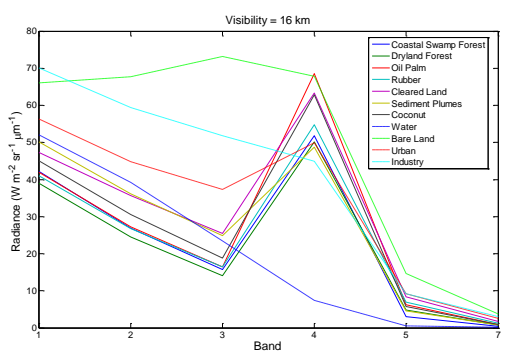

(a)

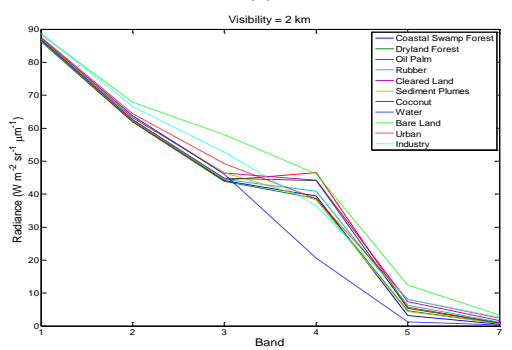

(b)

Fig. 7. Mean Spectral Signatures of the 12 Classes at Visibilities (a) 16 and $2 \mathrm{~km}$. 

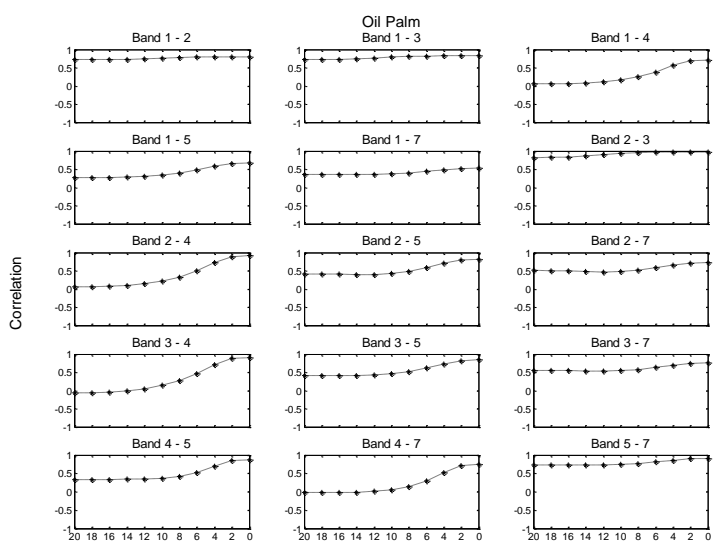

Visibility (km)

(a)
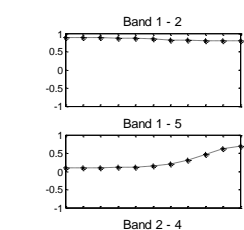

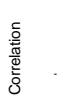
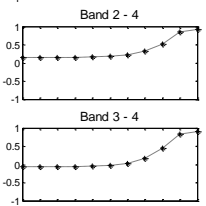

Band 4 - 5
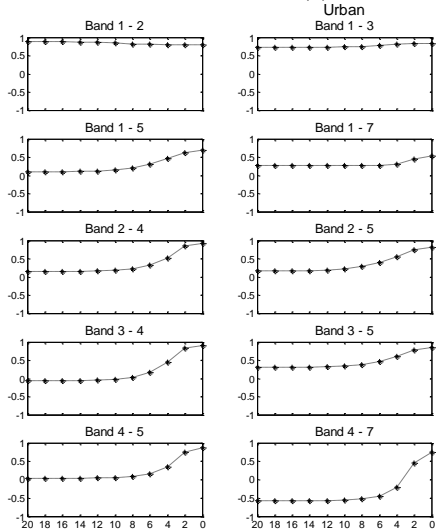

Band $1-7$
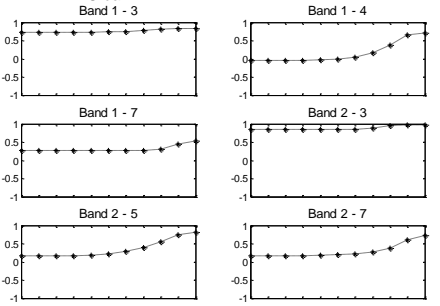

Band 3 - 5
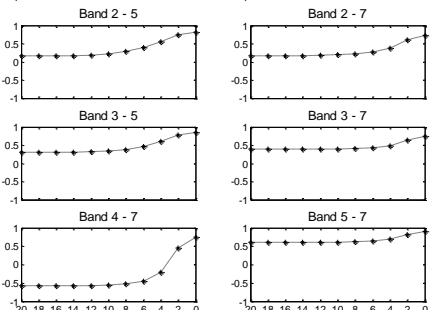

Visibility (km)

(b)

Fig. 8. Correlation between bands with Reducing Visibility for (a) Oil Palm and (b) urban.

Subsequently, classification accuracy versus visibility was plotted for all 11 land covers as shown in Fig. 9 [13], [14]. As expected, a drop in accuracy can be seen as visibility gets low. However, the drop trend varies for different land covers. Due to the similar physical properties, oil palm and coconut show somewhat similar trend. Similarly, a common trend also can be seen for dryland forest and rubber. A faster drop can be seen for industry compared to others particularly due to mixed pixels issue. It is also obvious that accuracy drop for water only occurs at $2 \mathrm{~km}$ visibility due to the fact that water has somewhat uniform spectral properties and tend to be classified correctly at $20 \mathrm{~km}$ downto $2 \mathrm{~km}$ visibility.

The reason for the drop in accuracy can be clarified by plot of pixels versus classes for oil palm and urban as shown in Fig. 10. Different coloured lines indicate different visibilities. In an ideal situation, when classified as oil palm. Oil palm pixels should be $100 \%$ at all visibilities as for $20 \mathrm{~km}$ visibility. However, migration of oil palm pixels to other land cover classes seems to occur as visibility reduces causing a decrease in classification accuracy.

To understand the overall trend on how haze affects classification, overall classification accuracy versus visibility was plotted for $20 \mathrm{~km}$ downto o $\mathrm{km}$ visibility images. Overall classification accuracy and Kappa coefficient versus visibility are shown in Fig. 11.

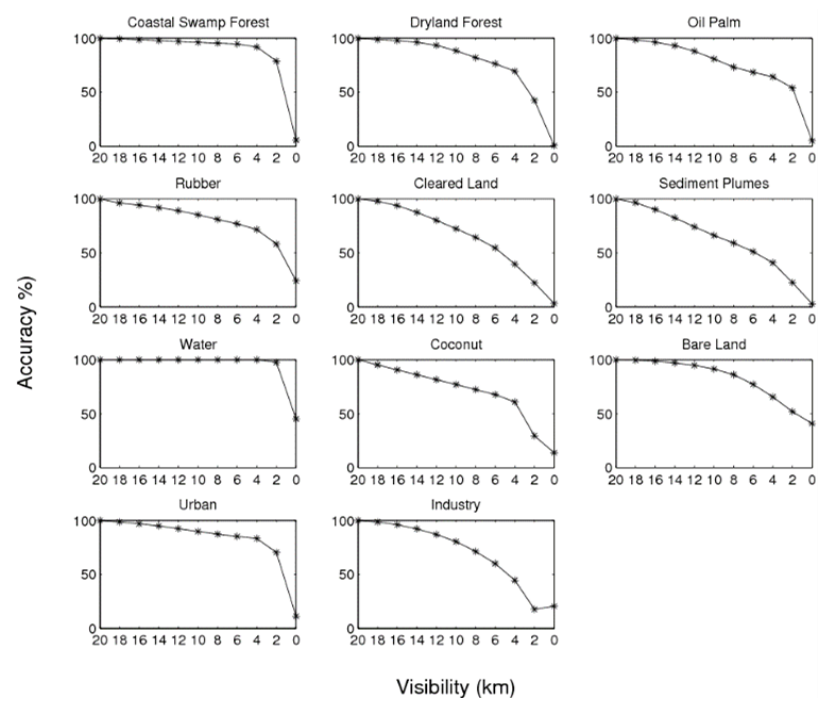

Fig. 9. Classification Accuracy for Each Class with Reducing Visibility.

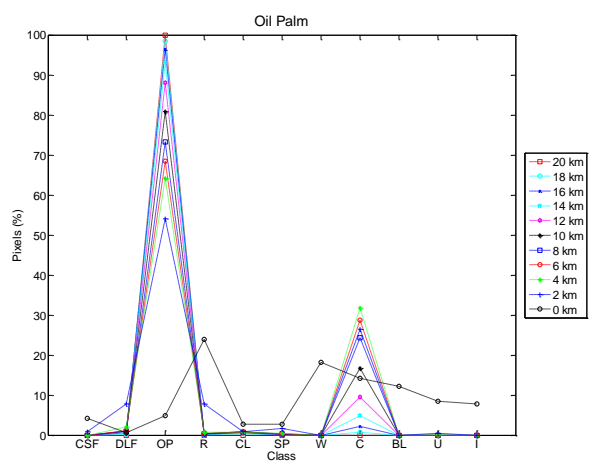

(a)

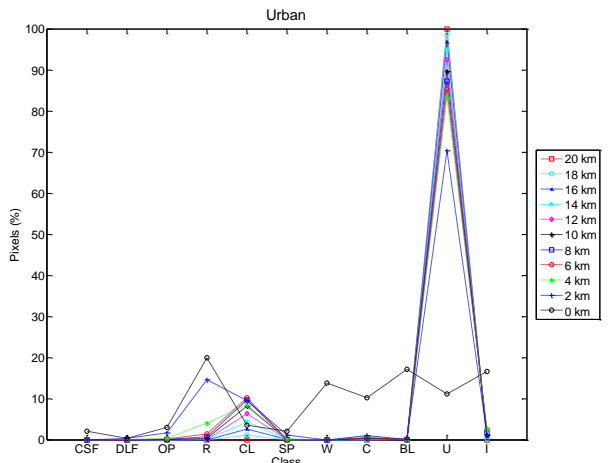

(b)

Fig. 10. Percentage of Pixels for (a) Oil Palm and (b) urban.
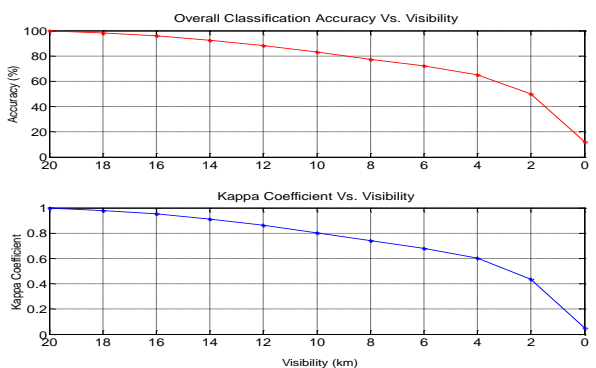

Fig. 11. Overall Classification Accuracy (top) and Kappa Coefficient (Bottom) Versus Visibility. 


\section{HAZE CORRECTION}

This section attempts to correct for the haze effects based on the findings in the previous sections. The simulated hazy images undergo mean subtraction and three types of filtering, namely average, median and Gaussian. The signal-to-noise (SNR) of the filtered images versus visibility were plotted for each filtering type. The outcomes are shown in Fig. 12.

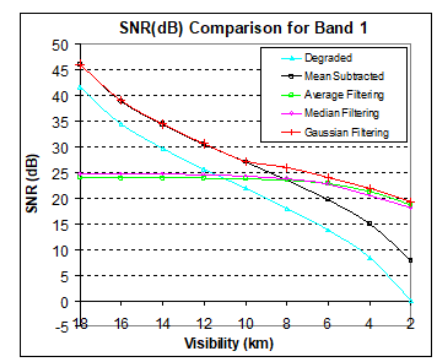

(a)

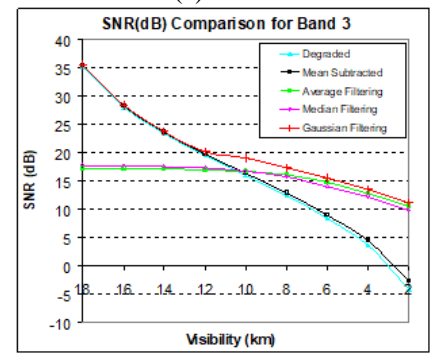

(c)

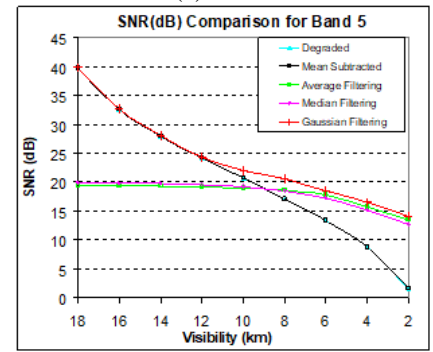

(e)

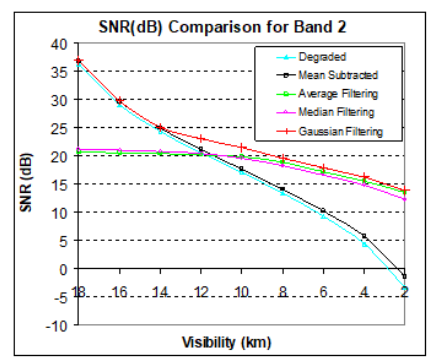

(b)

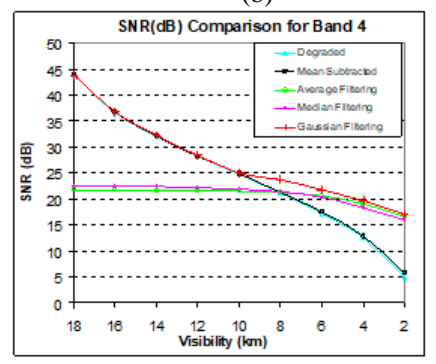

(d)

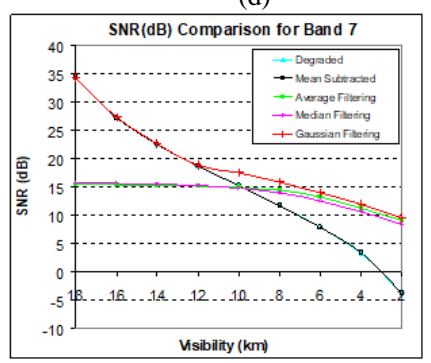

(f)
Fig. 12. SNR Versus Visibility for Degraded images, after mean Subtraction and after Applying Average Filtering, Median Filtering, and Gaussian Filtering for band 1, 2, 3, 4, 5 and 7 (a to f).

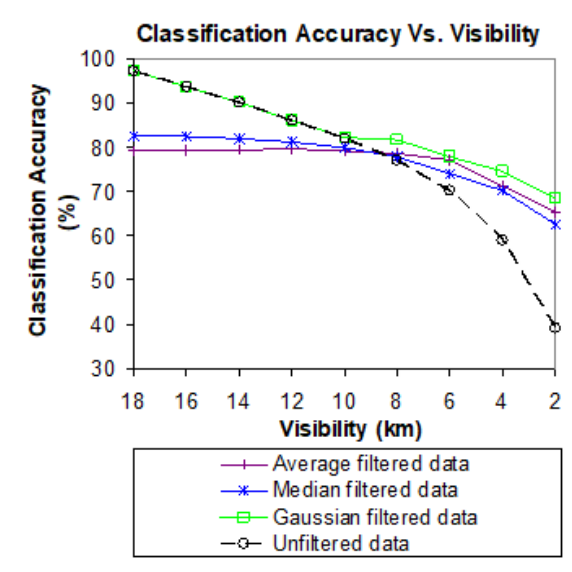

Fig. 13. Classification Accuracy Against Visibility for Average, Median and Gaussian Filtering

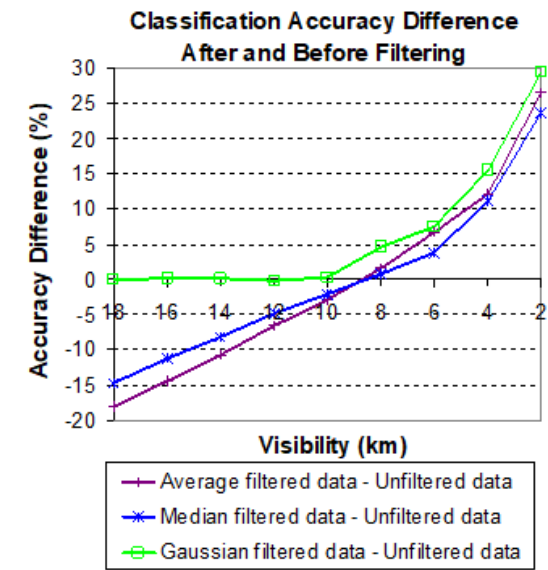

Fig. 14. Accuracy difference between Filtered and unfiltered Images for Average, Median and Gaussian Filtering.

To examine how far the haze correction is able to improve the hazy images, we plotted classification accuracy versus visibility for filtered and unfiltered images for average, median and Gaussian filtering. The accuracy difference between after and before filtering was also determined to predict the improvement made for the hazy images. Fig. 13 shows classification accuracy against visibility for average, median and Gaussian filtering. Fig. 14 shows accuracy difference between filtered and unfiltered images for all the three types of filtering.

\section{IMPLEMENTATION ON REAL HAZY IMAGES}

Based on the outcomes from the previous sections, a procedure was developed to implement the haze correction on real hazy images. The procedure can be represented by a flowchart as shown in Fig. 15. The study area within the real hazy images was located in Selangor, Malaysia. Based on the flowchart, the haze correction procedure involves two key phases, namely haze removal and quality assessment.

\section{A. Haze Removal}

The real hazy images were initially examined to check whether having uniform haze or not. If the haze was uniform, the weighted haze mean was to be estimated based on pseudoinvariant features (PIF) technique and subtracted from the hazy images [15]. On the other hand, if the haze was not uniform, the haze was to be segmented first using minimum noise fraction (MNF) technique. Subsequently, Gaussian spatial filtering was performed onto the hazy images [16].

\section{B. Quality Assessment}

In this phase, the performance of the haze correction was to be quality assessed. For such purpose, ML classification was first performed onto the hazy images. Finally, classification accuracy was calculated and examined.

The result is of the implementation is shown in Fig. 16. The top row shows the colour composite image of band 3,2 and 1 assigned to red, green and blue respectively. The middle row shows ML classification while the bottom row shows the corresponding enlarged version. The left and middle column shows the image before and after haze removal while the right column shows the clear image representing non-hazy 
condition. Visually, in the top row, the middle image shows that most of the haze have been eliminated, making it looked very close to the clear image in the right column. This is more obvious as can be seen from the images in the third row. A more significant effect can be seen on dark areas [16], [17], [18], [19]. In the second row, the misclassification between urban, rubber and cleared land as can be seen in the first column has been corrected making the classification very close to that of the right column. In the third row, the effects before and after the haze correction can be seen more clearly in the selected area. The outcomes also suggest that dealing with homogenous haze is likely to be simpler compared to heterogenous haze [20], [21], [22], [23].

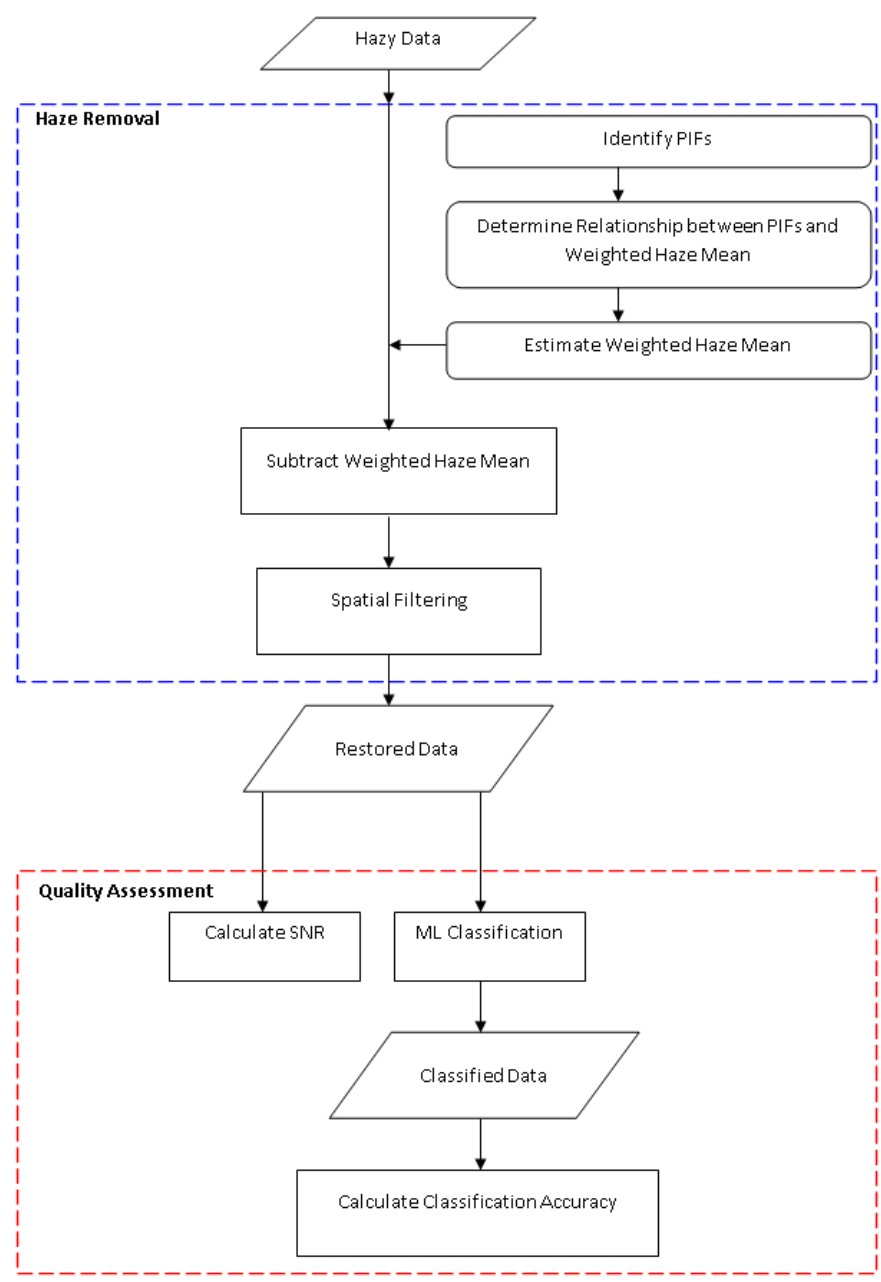

Fig. 15. Flowchart of the Haze Removal and Quality Assessment Procedures using Real Hazy Images.

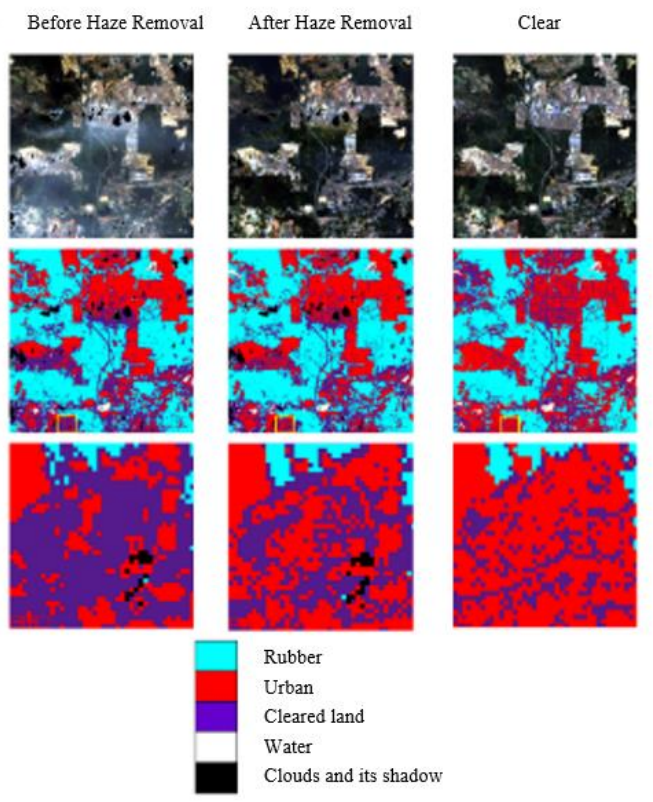

Fig. 16. Colour Composite Image of Band 3, 2 and 1 Assigned to Red, Green and Blue (Top Row) Respectively, ML Classification (Middle Row) and the Corresponding Enlarged Version (Bottom Row) before and after Haze Removal (Left and Middle Column) and the Clear Image (Right Column). The Enlarged Version Represents the Area within the Yellow Box in the ML Classification Image.

\section{CONCLUSIONS}

In this paper, haze effects on remote sensing imagery and their corrections have been studied. To understand the effects of haze on remote sensing imagery, haze was initially simulated over real remote sensing images to represent hazy images. Spectral signature analysis, correlation analysis and classification accuracy analysis have been carried out to assess the effects of haze on the simulated hazy images. Subsequently, a methodology for correcting haze has been developed involving weighted mean subtraction and filtering for correcting haze. For assessing the quality of the corrected images, SNR and classification accuracy have been used. Eventually the developed haze correction has been tested onto real hazy images. The result shows that the method was able to remove most haze from the hazy images effectively. The developed method is expected able to increase the reliability of remote sensing data in haze affected areas. However, the performance of the method might be hampered by heterogenous haze since the haze mean reflectance cannot be easily subtracted. Future studies should seriously look into this matter to ensure remote sensing imagery can be used optimally in various applications for the benefit of mankind. 


\section{ACKNOWLEDGMENT}

The Authors are grateful to Universiti Teknikal Malaysia Melaka (UTeM) for providing the funding and support for this research.

\section{REFERENCES}

[1] New Straits Times, 2019. Haze: Haze in Sri Aman hits 'hazardous' level, API at 407 (Updated 17 September 2019). Available at: https://www.nst.com.my/news/nation/2019/09/522107/haze-sri-amanhits-hazardous-level-api-407 [Accessed: 25 September 2019].

[2] Academy of Sciences Malaysia, "Air quality and haze episodes in Malaysia”. Stakeholder Consultation Workshop, 2016.

[3] The Star Online, 2005. Open burning in Klang Valley banned (Updated 9 August 2005). Available at: http://www.thestar.com.my/news/story. asp?file=/2005/8/9/nation/11717460\&sec=nation [Accessed: 13 September 2019].

[4] Department of Environment 2000, A Guide to Air Pollutant Index (API) in Malaysia. Department of Environment, Kuala Lumpur.

[5] Department of Environment. Air Quality. [online] Available at: https://www.doe.gov.my/portalv1/wp-content/uploads/2013/01/AirQuality.pdf, 2019 [Accessed 30 Aug. 2019].

[6] Department of Environment. Air Pollutant Index (API). [online] Available at: https://www.doe.gov.my/portalv1/en/info-umum/englishair-pollutant-index-api/100, 2019 [Accessed 30 Aug. 2019].

[7] S.Y. Kotchenova and E.F.Vermote, "Validation of a vector version of the $6 \mathrm{~S}$ radiative transfer code for atmospheric correction of satellite data. Part II: Homogeneous Lambertian and anisotropic surfaces," Applied Optics, vol. 46, no. 20, pp. 4455 - 4464, 2006.

[8] S.Y. Kotchenova, E.F. Vermote, R. Matarrese and F.J. Klemm Jr., "Validation of a vector version of the $6 \mathrm{~S}$ radiative transfer code for atmospheric correction of satellite data. Part I: Path Radiance," Applied Optics, vol. 45, no. 26, pp. 6726-6774, 2006.

[9] A. Ahmad and S. Quegan, "Haze modelling and simulation in remote sensing satellite data," Applied Mathematical Sciences, vol. 8, no. 159, pp. 7909-7921, 2014.

[10] U.K.M. Hashim and A. Ahmad, "The effects of training set size on the accuracy of maximum likelihood, neural network and support vector machine classification," Science International-Lahore, vol. 26, no. 4,. pp. 1477-1481, 2014.

[11] A. Ahmad, U.K.M. Hashim, O. Mohd, M.M. Abdullah, H. Sakidin, A.W. Rasib and S.F. Sufahani, "Comparative analysis of support vector machine, maximum likelihood and neural network classification on multispectral remote sensing data "International Journal of Advanced Computer Science and Applications(IJACSA), vol.9, no. 9, pp. 529 537, 2018.

[12] A. Ahmad and S. Quegan, "The effects of haze on the spectral and statistical properties of land cover classification," Applied Mathematical Sciences, vol. 8, no. 180, pp. 9001-9013, 2014.

[13] A. Ahmad and S. Quegan, "The effects of haze on the accuracy of satellite land cover classification," Applied Mathematical Sciences, vol. 9, no. 49, pp. 2433-2443, 2015.

[14] M.F. Razali, A. Ahmad, O. Mohd and H. Sakidin, "Quantifying haze from satellite using haze optimized transformation (HOT)," Applied Mathematical Sciences, vol. 9, no. 29, pp. 1407 - 1416, 2015.

[15] H. Zhou, S. Liu, J. He, Q. Wen, L. Song and Y. Ma, "A new model for the automatic relative radiometric normalization of multiple images with pseudo-invariant features," International Journal of Remote Sensing, vol. 37, no. 19, 4554 - 4573, 2016.

[16] G. Luo, G. Chen, L. Tian, K. Qin and S. Qian, "Minimum noise fraction versus principal component analysis as a preprocessing step for hyperspectral imagery denoising," Canadian Journal of Remote Sensing, vo. 42, no. 2, $106-116,2016$.

[17] S. Haouassi, W. Di, M. Hamidaoui and T. Rachida, "An efficient image haze removal algorithm based on new accurate depth and light estimation algorithm" International Journal of Advanced Computer Science and Applications (IJACSA), vol. 10, no. 4, pp. 64 -76, 2019.

[18] K.B. Gibson, D.T. Vo, T.Q. Nguyen, "An investigation of dehazing effects on image and video coding," IEEE Transaction on Image Processing, pp. 662-673, 2012.

[19] Q. Zhu, S. Yang, P.A. Heng, X. Li, "An adaptive and effective single image dehazing algorithm based on dark channel prior," IEEE International Conference on Robotics and Biomimetics, 2013.

[20] J.P. Tarel, N. Hautiere, L. Caraffa, ; A. Cord, H. Halmaoui, D. Gruyer,"Vision enhancement in homogeneous and heterogeneous fog," IEEE Intelligent Transportation Systems Magazine, pp. 6-20, 2012.

[21] K. Tang, J.C. Yang, J. Wang, "Investigating haze-relevant features in a learning framework for image dehazing". IEEE Conference on Computer Vision and Pattern Recognition, 2014.

[22] A. Singh, "Review article digital change detection techniques using remotely-sensed data," International Journal of Remote Sensing, vol. 10, no. 6, pp. 989-1003, 1989.

[23] K.R. Manjula, J. Singaraju J. and A.K. Varma, "Data preprocessing in multi-temporal remote sensing data for deforestation analysis," Global Journal of Computer Science and Technology Software \& Data Engineering, vol. 13, no. 6, pp. 1-8, 2013. 